\title{
Post partum diastasis of the pubic symphysis: a case report
}

\author{
Islam $M A^{1}$, Ali $M A^{2}$, Beg $A^{3}$, Chowdhury $F^{4}$, Ansary $\mathrm{NB}^{5}$, Quddus $M A^{6}, \operatorname{Nag} M N^{7}$, Based $M A^{8}$.
}

\begin{abstract}
The post partum diastasis ( means separation) of pubic symphysis is an uncommon disease. It causes acute pelvic pain. Manual pressure to the pelvis in a latero-lateral and antero-posterior direction worsens the condition. The diagnostic test for this condition is an anteroposterior X-ray of the pelvis. Here we present a case following spontaneous vaginal delivery. The conservative treatment is able to obtain good results. If this disease is underestimated the patient can develop chronic pain.
\end{abstract}

CBMJ 2013 Jan: Vol-02, No-01: P: 73-75

Key words: Diastasis, pubic symphysis, post partum.

\section{Introduction}

The pubic symphysis is a secondary cartilaginous joint classified as amphiarthrosis covered by a layer of hyaline cartilage with an interposed, softer fibrocartilagineous disc acting as a buffer. This joint allows only very limited movements except under hormonal stimulation during the third trimester of pregnancy or during birth when it becomes progressively loosen. In normal conditions these movements are in the range of 0.5-1 $\mathrm{mm}^{1}$. Starting from the seventh month of pregnancy a widening of the sacro-iliac joint and the pubic symphysis occurs $(4-8 \mathrm{~mm})^{2}$. The articular surfaces of pubic symphysis have been the subject of numerous studies because they change with age. During adolescence they show irregular edges while at 30 years of age they become oval-shaped. Between 40 and 50 years of age the surfaces become smoother, and at 60 years they become rougher and progressively eroded ${ }^{3}$. Each diastasis over $10 \mathrm{~mm}$ in males and $15 \mathrm{~mm}$ in females is considered a subdislocation or a gap ${ }^{1}$. According to Kraus (1930), the physiological width of the normal cleavage seen on X-rays is age related. It is $10 \mathrm{~mm}$ at the age of $3,6 \mathrm{~mm}$ at 20 , and $3 \mathrm{~mm}$ at 50 years ${ }^{4}$. A diastasis wider than $14 \mathrm{~mm}$ indicates concomitant damage of the sacroiliac joint with anterior lacerations on one or both sides of the ventral sacro-iliac ligament. A diastasis of the pubic symphysis after birth is a rare ${ }^{5}$ but painful complication that causes serious distress to the patient. When this occurs, adequate treatment should be given while keeping in mind the needs of the mother and the baby.
1. Dr Md Aminul Islam

Associate Professor, Dept. of Medicine, Ad-din Women Medical College Hospital, 2 Bara Maghbazar, Dhaka - 1217.

2. Dr Md Akmat Ali Assistant Professor, Dept. of Hepatology, Addin Women Medical College Hospital, 2 Bara Maghbazar, Dhaka - 1217.

3. Dr Ayesha Beg Medical Officer, Muktagacha Upazila Health Complex, Mymensingh.

4. Dr Ferdousy Chowdhury Assistant Professor, Dept. of Obstetrics and Gynaecology, Ad-din Women Medical College Hospital, 2 Bara Maghbazar, Dhaka - 1217.

5. Dr Nahid Bintay Ansary Associate Professor, Department of Physiology, CBMCB, Mymensingh.

6. Prof MA Quddus Professor and Head, Dept. of Radiology, Addin Women Medical College Hospital, 2 Bara Maghbazar, Dhaka - 1217.

7. Professor $\mathrm{MNNag}$ Professor and Head, Dept. of Medicine, Ad-din Women Medical College Hospital, 2 Bara Maghbazar, Dhaka - 1217.

8. Professor MA Based Professor and Head, Dept. of Orthopaedics, Ad-din Women Medical College Hospital, 2 Bara Maghbazar, Dhaka - 1217.

\section{* Address of Correspondence: E-mail: aminul1712@gmail.com Mobile : 01712116214}


In an ultrasonographic study carried out on women in labour, Scriven et al found that the incidence of pubic diastasis is 1 out of 800 patients ${ }^{6}$. Other reported incidence of nontraumatic diastasis varies widely, from 1 in 300 pregnancies to 1 in 30,000 pregnancies. In a nonpregnant woman, the normal pubic symphysis gap ranges from 4 to $5 \mathrm{~mm}$. With pregnancy, the gap increases by at least 2 to $3 \mathrm{~mm}$, which is thought to be caused by the slackness of ligaments supporting the joint. The diagnosis of diastasis is based on the persistence of symptoms and a symphysis pubis separation of more than 10 to $13 \mathrm{~mm}$ on imaging ${ }^{12}$. Clinically, the patient complains of pain, with swelling and sometimes deformity appearing in the involved area. In some cases it is possible to hear a clicking sound when the patient walks. The pain increases when manual pressure is applied to the pelvis in a latero-lateral and antero-posterior direction. If the dislocation is severe it can be accompanied by shock. A small percentage of patients can develop chronic pain requiring a surgical intervention of debridement or a pubic symphysis fusion ${ }^{7}$. The diagnostic test for this condition is an anteroposterior X-ray of the pelvis. Lesions along the genito-urinary tract may also be present. In an emergency, it is advisable to lie the patient in lateral decubitus. In ultrasonographic study, Scriven shows a direct link between the permanence of the symphysis gap and the presence of chronic pain. The treatment can be surgical or conservative.

\section{Case report}

We have been consulted by the Department of Gynaecology and Obstetrics of our Hospital regarding a case of severe post partum back pain. Mrs Maya Rani 38 years old lady hailing from Mohakhali, Dhaka at her 37 weeks of pregnancy with labour pain. She is married for 25 years, gravida 2 , para $1+0$, age of last child is 14 years which was delivered per vaginally. She was moderately oedematous and her blood pressure was 180/110 $\mathrm{mmHg}$ on admission, urinary albumin was $1+$. Per vaginal examination showed OS $9 \mathrm{~cm}$, membrane ruptured, station -1 , caput $2+$. With proper control of blood pressure spontaneous vaginal delivery was occurred at lithotomy position. The baby was of normal dimensions. She weighed $3.3 \mathrm{~kg}$, was $51 \mathrm{~cm}$ long, occipito-frontal circumference was 35 $\mathrm{cm}$. The total duration of delivery of baby was 2 hours and 45 minutes. The placenta was deliverded spontaneously within 5 minutes. On the first day of puerperium she developed severe low back pain with severe limitation of pelvic movement including abduction and adduction of hip joints and pelvic movement was very much painful. The woman was overweight $(68 \mathrm{~kg})$ and height was 4 feet 10 inches. On physical examination it was observed that the pain was over the sacrum. All the osteotendinous reflexes were normal, and the Lasegue's sign was negative. There was a gap near the pubic symphysis. Palpation caused the patient a great deal of pain. Walking was difficult because of the pain and the external rotation of the right lower limb. An X-ray pelvis AP view showed diastasis of approximately $17 \mathrm{~mm}$ (figure 1 ) at symphysis pubis which is almost $4-8$ times higher than normal limit. On her management she advised bed rest in lateral decubitus position, analgesic, pelvic brace and physiotherapy and to continue antihypertensive. Patient improved with this and discharged on request 4 days later. She was further followed up, she had no complain of pain and local no gap is evident and can walk normally.

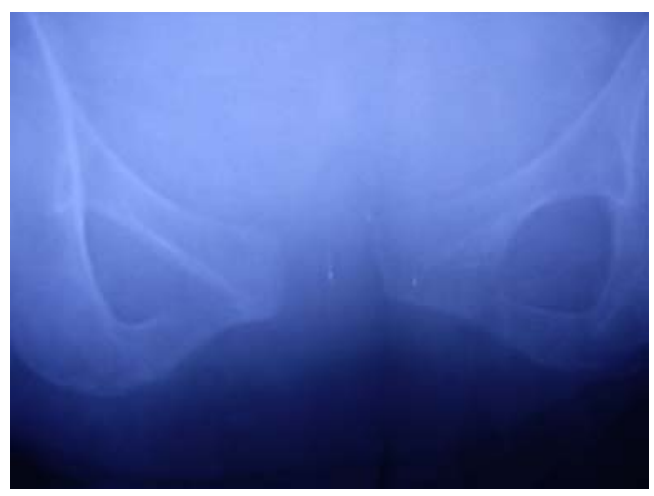

Figure 1: X-ray pelvis AP view showed $17 \mathrm{~mm}$ gap of symphysis pubis. 


\section{Discussion}

A pubic diastasis must be suspected if the patient complains of post partum acute and persistent pain in the pelvic area. The treatment can be conservative or surgical. Treatment is conservative, with bed rest and gradual mobilization if the diastasis is less than $25 \mathrm{~mm}$, but extreme cases may require surgery. Although the condition may recur, the prognosis for subsequent pregnancies remains good. The patient was treated with oral analgesics and physical therapy, with excellent results ${ }^{12}$. Many Authors advise ${ }^{7,8}$ the conservative treatment, which is the method we followed. In the first phase, this treatment consists in lying in a lateral position whose function is to reduce the pelvic dislocation through pressure exerted by the weight of the patient. In the second phase a pelvic condilar plaster or a binder or brace is used to ensure the patient's immobilization. On emergency, the surgical treatment, aimed at reducing and stabilizing the dislocation, can be done with an external fixator. Otherwise, a plate with screws can be fixed on the pelvic area, as suggested by $A O 9$. Other devices, such as wires, are used in this kind of pathology: in 1951, in Rome, Prof. Carlo Marino Zuco ${ }^{10}$ advised the reduction and stabilization of the dislocation through the use of two $\mathrm{K}$ wires which are crossed and tied to the pubic symphysis itself. We consider the choice of conservative treatment when the following conditions are present: i) good possibility of obtaining and maintaining an acceptable gap reduction, ii) a favourable evolution of the condition as described in the medical literature, iii) aversion to surgical reduction and synthesis because of problems deriving from surgery which would indirectly affect the new born. In fact, the mother could not breast-feed the baby because of anaesthetics, antibiotics and thromboembolic prophylaxis if received. We must remember, however, that a surgical intervention would have achieved the desired anatomical reduction and greater stability. This method, however, in a few cases can lead to complications such as urinary infections ${ }^{11}$. In addition, a synthesis with plate and screws would lead to a cesarean birth if the patient becomes pregnant again.

\section{References}

1. Simon RR, Koenigsknecht SJ. Emergenze ortopediche: estremità e bacino. Edizioni Minerva Medica 2002: 373.

2. Americans college of surgeons. Advanced trauma life support for doctors, 1997: 346.

3. Lockhart $R D$, et al. Anatomia del corpo umano. Casa Editrice Milano 1992: 1.

4. Kuner E, Schlosser V: Handbook di Traumatologia. Mediserve, 1992: 326.

5. Seth S, Das B, Salhan S. A severe case of pubic symphysis diastasis in pregnancy. Eur $\mathrm{J}$ Obstet Gynecol Reprod Biol 2003; 106 (10): 230-2.

6. Scriven $M W$, Jones DA, McKnight L. The importance of pubic pain following childbirth: a clinical ultrasonographic study of diastasis of the pubic symphysis. JR Soc Med 1995; 88: $28-30$

7. Dunbar RP. Puerperal diastasis of the public symphysis. A case report. J Reprod Med 2002; 47: 581-3.

8. Omololu AB, Alonge TO, Salawu SA. Spontaneus pubic symphysial diastasis following vaginal delivery. Afr J Med Med Sci 2001; 30: 133-5.

9. Ruedi TP, et al. Principi AO per il trattamento delle fratture. CIC Edizioni internazionali, 2002.

10. Zuco CM. Mezzi della moderna osteosintesi in traumatologia. XXXVI congresso SIOT, 244.

11. Heetveld MJ, Poolman RW. Spontaneus expulsion of a screw durino urination: an unusual complications after 9 years after internal fixation of pubic symphysis diastasis. Urology 2003; 61: 645.

12. Parker JM, Bhattacharjee M. Peripartum diastasis of symphysis pubis. N Engl J Med, 2009; 361; 19: 1886. 